\title{
REPORT
}

\section{Supporting the Changing Research Practices of Asian Studies Scholars}

June 21, 2018

Danielle Cooper

Katherine Daniel

$\begin{array}{lll}\text { Jade Alburo } & \text { Michael J. Hughes } & \text { Meng-fen Su } \\ \text { Deepa Banerjee } & \text { Ramona Islam } & \text { Azusa Tanaka } \\ \text { Tomoko Bialock } & \text { Michaela Kelly } & \text { Yukako Tatsumi } \\ \text { Hong Cheng } & \text { Richard Lesage } & \text { Brian Winterman } \\ \text { SuChen } & \text { Xiang Li } & \text { Lijuan Xu } \\ \text { Sanghun Cho } & \text { Carrie Marsh } & \text { Hyokyoung Yi } \\ \text { Karen Stoll Farrell } & \text { Kuniko Yamada McVey } & \text { Xiuying Zou } \\ \text { Ralph Gabbard } & \text { Mary Rader } & \\ \text { Judith A. Henchy } & \text { Bonnie Brown Real } & \\ \text { David Hirsch } & \text { Zhijia Shen } & \\ \text { Michael Hopper } & \text { Cynthia Sorrell } & \end{array}$

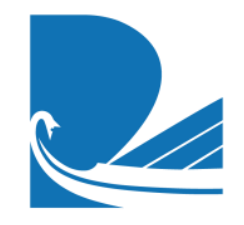




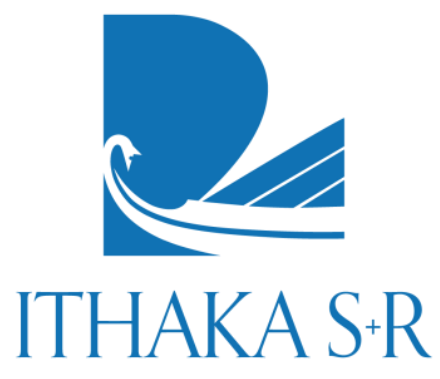

Ithaka $\mathrm{S}+\mathrm{R}$ provides research and

Copyright 2018 ITHAKA. This work is strategic guidance to help the academic and cultural communities licensed under a Creative Commons Attribution-NonCommercial 4.0 International License. To view a copy of serve the public good and navigate economic, demographic, and technological change. Ithaka $\mathrm{S}+\mathrm{R}$ is part of ITHAKA, a not-for-profit organization that works to advance and preserve knowledge and to the license, please see http://creativecommons.org/licenses/by-nc/4.0/.

ITHAKA is interested in disseminating this brief as widely as possible. Please contact us with any questions about using the report: research@ithaka.org improve teaching and learning through the use of digital technologies. Artstor, JSTOR, and Portico are also part of ITHAKA.

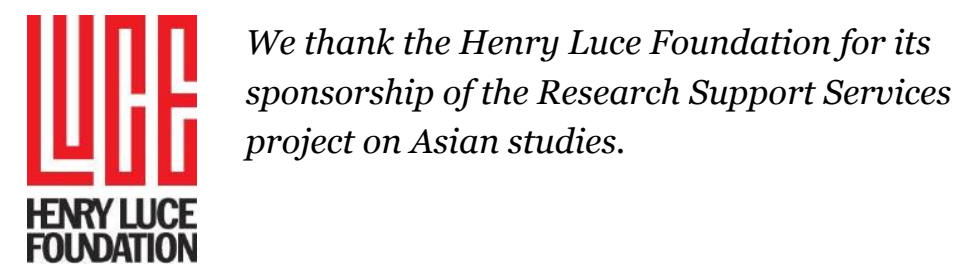




\section{Contents}

Executive Summary ………………............................................................... 3

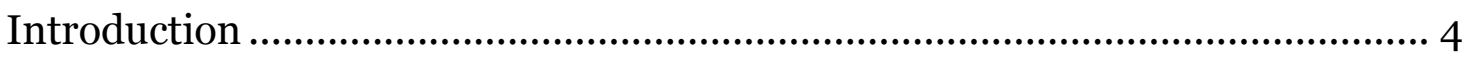

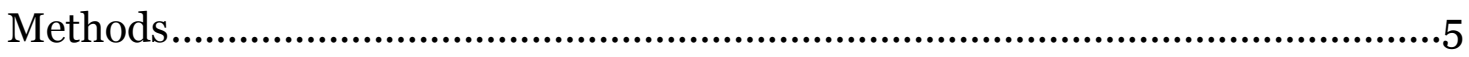

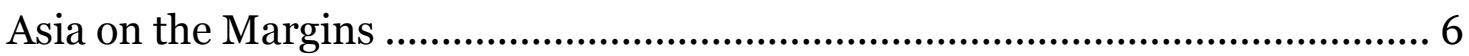

Discovery and Access .................................................................................... 9

Research Workflow Management..............................................................19

Outputs, Audience, and Impact ....................................................................... 23

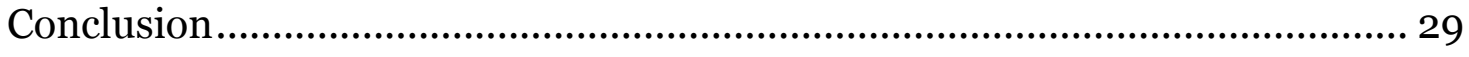

Recommendations ….................................................................................... 32

Appendix 1: Research Teams and Local Reports ............................................... 36

Appendix 2: Semi-Structured Interview Guide .................................................. 38 


\section{Executive Summary}

Ithaka S+R's Research Support Services Program investigates how the research support needs of scholars vary by discipline and includes reports on history, chemistry, art history, religious studies, agriculture, and public health. In 2017-2018, Ithaka S+R examined the changing research methods and practices of Asian studies scholars conducting research through U.S. institutions. This project was undertaken collaboratively with research teams at 11 academic libraries with the goal of identifying services to better support Asian studies scholars. This report aims to provide actionable findings for the organizations, institutions, and professionals who support the research process of Asian studies scholars. One hundred and sixty-nine scholars were interviewed during the project, and Ithaka $\mathrm{S}+\mathrm{R}$ sampled 50 of the resulting transcripts for the analysis presented in this report. These transcripts yielded findings in several thematic areas in which Asian studies would benefit from new or improved services, including its position within the academy, discovering and accessing information, managing research workflows, and producing outputs that reach target audiences and have the desired impact. Within these areas, we identified the following key challenges:

- Asia on the Margins. Scholars perceive area studies to be an outdated concept and struggle to identify their role within this umbrella given how broad the field is. They experience siloing along traditional disciplinary lines, which leads to lost opportunities to address the study of Asia from a more interdisciplinary and transregional perspective.

- Discovery and Access. Finding and keeping up with relevant information is a challenge that is compounded by different publishing conventions and categorization systems in Asia. Digitization has facilitated discovery and access in both the U.S. and Asia, but rates of digitization vary widely across Asian countries. Where digitization has improved, governments and other interests can more effectively control which information to share with scholars. Geopolitical and historical tensions, as well as language skills, act as barriers to scholars being able to easily access information.

- Research Workflow Management. The ability to personally create digital copies of information has facilitated data collection tremendously, but scholars are not always able to document their information in this manner. They have difficulty using digital software to manage information published in non-Roman scripts, and they also struggle to store and preserve ephemeral or difficult-to-obtain data. While these challenges are not unique to Asian studies scholars, they are particularly acute for scholars in this field where traveling and working with content obtained beyond the West is central.

- Outputs, Audience, and Impact. Asian studies scholars in the West are confronted with the challenge of balancing the publishing expectations of their home institutions with mechanisms that make their work more accessible to their peers in Asia. Differing publishing procedures and requirements for promotion at Asian universities restrict the ability of scholars in Asia and the U.S. to engage in collaborative or interdisciplinary research to a greater extent. 


\section{Introduction}

A scholar-centered approach to understanding research in higher education is crucial to developing information services and spaces, while a sustained approach to studying different disciplines over time also leads to a better understanding of how research activity functions across the academy. In recognition of this, Ithaka S+R's Research Support Services (RSS) program conducts in-depth qualitative analysis of the research practices and associated support needs of scholars by discipline towards better understanding changing research methods and practices. Our previous projects in the program studied scholars in history, chemistry, art history, religious studies, agriculture, and public health. ${ }^{1}$

An analysis of Asian studies scholars' research needs is particularly significant as Asia's global presence continues to grow. Geographically, the continent spans from the Arctic Circle to south of the equator, from Turkey's Bosporus Strait and Russia's Ural Mountains on its western border, to within fifty-five miles of touching Alaska at the Bering Strait's narrowest point on its eastern border. Demographically, the continent comprises 4.5 billion individuals as of 2016-half the world's population-spread out across forty-eight countries. With the region's growing economic and political influence in the international community, a better understanding of Asia's languages, cultures, and role in the world is increasingly germane.

In this report, we begin by exploring what it means to identify as an Asian studies scholar and the challenges and opportunities these scholars perceive for the future of their research. We then examine the ways in which these scholars discover and access information for topics that have been explored over the millennia in a field fraught with geopolitical and historical tensions; their research workflows from how they collect, manage, and store information; and how they create and disseminate research outputs, especially in regard to their peers based in Asia. We use these findings as the basis for proposing recommendations at the culmination of the report for various groups with

\footnotetext{
1 Jennifer Rutner and Roger Schonfeld, "Supporting the Changing Research Practices of Historians," Ithaka $S+R$, December 7, 2012, https://doi.org/10.18665/sr.22532; Matthew Long and Roger Schonfeld, "Supporting the Changing Research Practices of Chemists," Ithaka S+R, February 25, 2013, https://doi.org/10.18665/sr.22561; Roger Schonfeld and Matthew Long, "Supporting the Changing Research Practices of Art Historians," Ithaka S+R, April 30, 2014, https://doi.org/10.18665/sr.22833; Danielle Cooper, Roger C. Schonfeld, Richard Adams, Matthew Baker, Nisa Bakkalbasi, John G. Bales, Rebekah Bedard, et al, "Supporting the Changing Research Practices of Religious Studies Scholars," Ithaka S+R, February 8, 2017, https://doi.org/10.18665/sr.294119; Danielle Cooper, Sarah Bankston, Marianne S. Bracke, Beth Callahan, Hui-Fen Chang, Leslie M. Delserone, Florian Diekmann, et al, "Supporting the Changing Research Practices of Agriculture Scholars," Ithaka S+R, June 7, 2017, https://doi.org/10.18665/sr.303663; Danielle Cooper, Katherine Daniel, Caitlin Bakker, Jaime Blanck, Chris Childs, Ann Gleason, Rosie Hanneke, et al, "Supporting the Changing Research Practices of Public Health Scholars," Ithaka S+R, December 14, 2017 , http://doi.org/10.18665/sr.305867.
} 
mandates for supporting Asian studies: university administrators, libraries, publishers, tool developers, and funders.

\section{Methods}

\section{Developing the Asian studies Project}

This report is one component of a collaborative research project undertaken with 11 institutions, and we thank all the institutions that participated in this project. Participation was open to any U.S. higher education institution with an Asian studies research program that was able to conform to the project specifications (e.g. timeline, research capacity). The participating institutions created research teams whose members, following a training workshop designed and led by Danielle Cooper (Senior Researcher, Ithaka S+R), conducted semi-structured interviews with Asian studies scholars at their institution which Ithaka $S+R$ then analyzed for this report (see Appendix 2 for the semi-structured interview guide used for this project). Each research team also wrote local reports based on their own data and analysis (see Appendix 1 for a full list of the participants alongside their publicly available reports).

\section{Defining the Asian studies Scholar}

This report focuses on the practices and needs of Asian studies scholars in U.S. higher education. Reflecting the project's aim to focus on research as opposed to teaching activities, we defined "scholars" as individuals who are employed by their institutions with research as a significant component of their responsibility, as opposed to primarily teaching. Graduate students were not included in this study in recognition that their scholarly experiences are sufficiently unique to warrant separate attention beyond the scope of this study.

The majority of Asian studies scholars in the U.S. conduct research within the frameworks of humanistic disciplines such as history, literature, and religious studies, and social scientific disciplines including economics, political science, and sociology. Because Asian studies is inherently interdisciplinary, for the purposes of this report it is used to broadly describe participating scholars and the overarching theme of the research they undertake, while the term "discipline" is used to describe the specific subject matter that they research. Attention was given to ensure the participation of a broad scope of Asian studies scholars working in humanistic and social scientific disciplines and in different Asian countries. 
Scholars vary in the geographic breadth of their research; some conduct research on only one country, while others conduct transnational research within the same region and even across regions. To facilitate our sampling of transcripts, Ithaka S+R standardized regions of Asia by analyzing anonymized information about the interviewees and by reviewing classifications provided by academic and governmental institutions, which we have reconciled to the best of our abilities. We understand that our decision to place some countries and autonomous zones in the regions that we have may be viewed contentiously; these classifications do not intentionally reflect any political views. Our report focuses on the research needs and practices of scholars in three Asian regionsEast Asia, South Asia, and Southeast Asia-as well as the Asian-American diaspora. ${ }^{2}$ While a handful of scholars researching Central Asia and the Middle East were among the participants, we chose to concentrate on these four groups of scholars due to the volume of their transcripts. Using these standardized regions, we took care to categorize each of the 169 participating scholars according to the region(s) of Asia on which they primarily conduct their research.

\section{Asia on the Margins}

Asian studies as a field is itself a contested concept, with ramifications for how to frame research support services that resonate with scholars' needs. Scholars point to the start of the Cold War in the late 1940 s as the period of time when area studies first emerged. In establishing area studies programs, a number of scholars expressed that "universities in America...really focused on one region separately from other regions," while the West's hegemonic position had the further effect of casting peripheral areas as "other" that were examined within a Western theoretical framework. To illustrate this point, one scholar explained that "if you look at film studies departments in Europe or North America, or even often in East Asia, they mainly deal with North American and European films. So they are basically also doing area studies. They just don't acknowledge it." Seventy years on, many of the scholars interviewed for this report consider the idea of areas studies outdated. As one scholar said, "There is a lot of debate about is it even appropriate to just study Asia, because what is Asia and the study of Asia have been constructed particularly because of Cold War politics and area studies."

This debate is apparent in the ways that these scholars identify-or choose not to identify-with Asian studies. Some scholars placed themselves idiosyncratically along a spectrum, with some describing a broader affiliation with the field-"I would say I think

\footnotetext{
${ }^{2}$ Included in East Asia are China, Japan, North and South Korea, Taiwan, and Tibet. Included in South Asia are Bangladesh, India, and Pakistan. Included in Southeast Asia are Cambodia, East Timor, Indonesia, Myanmar, the Philippines, Thailand, and Vietnam.
} 
of myself as an Asianist"-and others a more granular one. For instance, one scholar said that "it's more intellectually modest thinking of myself as a mainland Southeast Asianist...I would be hesitant to call myself an Asianist just because I've spent almost a decade and a half trying very hard to cover an extremely small portion of a small place." Another said, "Sometimes I think my work is actually situated much better in Chinese studies than geography" because their research focuses more on an area than more broadly within their discipline.

However, a more common attitude expressed by these scholars is that their work is simply related to Asia rather than about Asia, and they therefore see their affiliation to Asian studies as tangential if they consider themselves to be part of Asian studies at all. In a comment similar to what many other scholars expressed, one interviewee noted, "I think of myself as a linguist...I have this areas studies component where I am very passionate about East Asia or Asia as a whole, [but] on the other side, I also want to really pursue linguistics." Another explained that "in economics they've already abandoned area studies for [a] long time" because in their discipline, for example, "you do this research about Vietnam but it's not about Vietnam, it's only a case study that provides evidence about [a] universal law" that could be applied anywhere else in the world.

The extent to which scholars are likely to align themselves with Asian studies as a field consequently relates to the degree that they associate their research with a specific geographic location. Social scientists and humanists alike explicitly identified as "Asianists," whether their research encompasses the whole continent or an exact region within Asia, but a number of scholars also perceive Asian studies to be humanistic in nature precisely because of its emphasis on countries, their cultures, and language pedagogy. Even among humanists, however, there was variation in the ways that they characterize themselves, with one scholar remarking, "I see myself as a historian but [a] historian of Asia...so I don't see any contradiction” in identifying as one or the other. Another suggested that despite the overlap, they would prefer to interact with peers whose interests are more closely aligned with theirs, saying, "I think I [would] find it more intellectually-engaging having colleagues in a religious studies department than I would having colleagues in an area studies department."

These comments are indicative of two main points of contention with how Asian studies is conceptualized. First, as many scholars contended, Asian studies has such a wide focus as to be a nearly meaningless classification. As one interviewee admitted, "[I]n all honesty, I think Asia is such a broad area...I'm sorry, I don't think there is such a thing as Asian studies." This view extends to scholars' engagement with the Association of Asian studies (AAS), the field's predominant academic organization. "It just includes too much of the world," one scholar said of their conference, "and their journal, the Journal of 
Asian studies, I rarely use it...it has so many articles on parts of Asia that I have no connection with whatsoever. Reading them would just be a waste of my time." While this view was prevalent, many scholars are members of AAS and attend its annual conference as a means of keeping up with research and accessing multidisciplinary points of view. "I get insight from a broad variety of scholars and disciplines by going to the conference and reading publications from AAS," explained one scholar, while another said that this conference is "where you hear what's the cutting edge research in different fields."

This interest in learning about Asia-related research being produced by scholars in other disciplines suggests a second point of contention: even as scholars say that Asian studies is too broad, they simultaneously express that they are often siloed by their countries of study and disciplines. "You have to know the language and you need deep training in not only the language but cultural sensitivity and history to claim specialty in that field, but the flip side of it is that they have this, like, tunnel vision," said one scholar, who describes this as a limitation that has factored heavily into their decision to sit in a department other than Asian studies. Moreover, scholars sense a threat to the continuing existence of Asian studies because, amid an increased push for specialization and disciplinary focus, "we've seen members formally in Asian studies go to their disciplinary departments because it's perceived to have more clout, more respect from other scholars." This has negative implications for interdisciplinary research, with scholars concerned that conducting their research in regional and disciplinary silos reduces the depth of their research and its potential impact. Furthermore, the marginalization that these scholars perceive has ramifications for their ability to acquire the materials that they need through their academic libraries, as will be discussed in the section "Research in the U.S.”

While not the focus of this project, it is important to highlight that Asian studies scholars' challenges resonate with those in other interdisciplinary fields. For example, Feminist Studies has a forthcoming issue, "Doctoral Degrees in W/G/S/F Studies: Taking Stock,” which features research from Melissa Autumn White, Carly Thomsen, and Stina Soderling that demonstrates how hiring in women's studies departments continues to favor those with PhDs in more traditionally defined fields over women's studies PhDs. Therefore, the experiences of Asian studies reflects a broader disjunction between some policies that seem to encourage interdisciplinary research in the academy and ongoing structural barriers that continue to limit the extent which these approaches can be meaningfully taken up. ${ }^{3}$

\footnotetext{
${ }^{3}$ Melissa Autumn White, Carly Thomsen, and Stina Soderling, "Critical Mass, Precarious Value? Reflections on the Gender, Women's, and Feminist Studies PhD in Austere Times," Feminist Theory, forthcoming, http://www.feministstudies.org/issues/forthcoming.html.
} 
While scholars see Asian studies' interdisciplinarity as a challenge, they also see this as an opportunity for re-conceptualizing Asian studies and the boundaries of interdisciplinary research more widely. "I think in the future we ought to be aiming for much more borderless approaches to research," said one scholar, with many others echoing that "the opportunities would be to really train scholars who can be conversant in transnational Asia or seeing Asia from a global perspective. And I think we need more training in that and more research support in that."

Regardless of whether or not these scholars identify with Asian studies, those whose research involves the study of Asia, to whatever extent, experience commonalities in their ability to successfully find and access information, manage and store their data, and produce outputs that reach their targeted academic and general audiences in specific regions. These commonalities traverse disciplinary affiliations, such as when a historian and an anthropologist go through the same tribulations in accessing government information in India, and will be discussed, along with their differences, in the remainder of this report.

\section{Discovery and Access}

Asian studies scholars struggle to discover relevant information and to keep up with the deluge of publications. Differing publication conventions and categorization systems in Asia can make it difficult for scholars to employ the same discovery methods as they do with Western publications. Scholars discussed the relative ease with which they are able to access information published and located in the U.S., but how they sometimes struggle to obtain obscure materials, especially in an academic setting where they often feel marginalized by their institutions. Additionally, they experience challenges in finding and accessing materials in libraries and archives overseas, as well as in obtaining information from human subjects. This was especially the case for countries with fraught geopolitical and historical tensions regarding the West or with relatively closed governments. Working with materials or participants in Asian languages was also mentioned as a barrier to discovery and access, although technological advances like Optical Character Recognition (OCR) and translation tools have alleviated this to an extent. Digitization has also facilitated information access in some countries, but has simultaneously increased the difficulty that some scholars experience in accessing information because of the greater control electronic access affords to officials.

\section{Finding and Keeping Up with Literature}

The international emphasis of Asian studies lends a unique element to the ways that these scholars discover and keep up with information. They employ many of the same 
tactics that scholars interviewed for previous RSS studies have described, including reading books, journals, and other items cited in their reference lists, attending meetings, utilizing professional networking sites and students, and browsing through databases or on search engines. ${ }^{4}$ But when searching for information published overseas, scholars have found that these usual methods may not be as applicable because of the different conventions and standards that scholars in Asia follow for their own publications. For example, one scholar mentioned that "Japanese scholarship tends not to have very complete bibliography citations," making it difficult for scholars to trace other sources to reference as they often do with the works cited in Western publications.

Similar to the challenges of relying on reference lists for information discovery when searching for non-Western literature, Asian studies scholars also reported needing to be creative when searching for literature using key words. For instance, a topic that receives relatively little interest in the U.S. can be a popular topic among scholars overseas, and using the same word in different languages will return a different number of results. One scholar described taking advantage of this feature of key word searches to manage the amount of literature they find, saying, "If the web cites [a Chinese word transliterated into English], in any publication, it generates an alert...I also do it in Chinese, but Chinese is too many. Every day there will be at least a dozen of them that have the word...but in English...there are one or two a week.” Key words are also subjective and can impose arbitrary limits on the information that scholars are able to find and subsequently use to inform their research. As one scholar said, "Often when you do a key word search, it doesn't [always] give you the materials you're really looking for," and added that "a big challenge was thinking about all the different kinds of key words and approaches" they needed to effectively broaden their search to include all the elements related to their project. Conversely, another scholar said that "[an archive] had the key word 'gun' in lots of things, where the title wouldn't give any indication that that's what it was about. So then it comes down to the group that's in charge of doing the data [entry] and metadata, and their decisions."

These comments suggest that the way that materials are cataloged by librarians and archivists can have a strong influence on not just facilitating the finding of information, but also on how a research topic is conceptualized. This is especially evident when concepts do not translate across cultures or when sensitive concepts are replaced with euphemisms. For instance, one scholar conducting research pertaining to a Western derogatory term for Asian peoples said that “[i]t is not even recognized as a category. It's

\footnotetext{
${ }^{4}$ See "Supporting the Changing Research Practices of Public Health Scholars," p.10-18; "Supporting the Changing Research Practices of Agriculture Scholars,' p.11-15; "Supporting the Changing Research Practices of Religious Studies Scholars," p.16, 22; "Supporting the Changing Research Practices of Art Historians," p.20-22; "Supporting the Changing Research Practices of Chemists," p.22-23; "Supporting the Changing Research Practices of Historians," p.14-17
} 
not even recognized as a key word...I feel like I'm doing research on a concept that was not even recognized as an important concept to be archived in its own category. So working against how [the] archive is categorized and organized, I feel like I'm going around the existing structure in trying to create my own structure." Scholars frequently mentioned having to work around the concepts implied through libraries and archives' cataloging systems, but often they do not know where to start when beginning research on topics with which they have less familiarity. Cross-disciplinary research poses a further complication because "you don't know what key word to put in sometimes when you're first learning about a subject.”

The emphasis placed on publishing as disciplines continue to grow in size has caused scholars to feel overwhelmed by the sheer amount of literature being produced today. One scholar said that when they started in academia in the 1970s, "I read everything in the field," but "if I read every minute of every day, I could not keep up with my sub-field right now, let alone the whole field." Because of the wealth of literature available, they additionally struggle with filtering information to only that which is relevant to their research. While scholars can and do employ hacks in an attempt to limit the literature they find, such as the previously mentioned scholar switching between the same search term in two languages, others more often expressed that they lack effective strategies and the technology to limit their searches. "I don't think there is currently a very good mechanism to tell me what has been published out there that is useful," said one scholar, while another said, "I need someone who can stand over my shoulder and say, 'Do not read these things, okay? Look at these other things."

Scholars often rely on peer networks to help them find and filter information for this relevance and quality. Students were regarded as especially knowledgeable about recent publications, with one scholar remarking that their students are their "eyes and ears" and another saying, "They're up on everything, and so I just make sure I read as much as I can that my students are reading." Professional networking sites like Academia.edu and ResearchGate were also described as useful for expediting and expanding discovery beyond the familiar journals and search engines that scholars tend to return to. According to one scholar, following their peers online through these channels "sometimes points me to very relevant materials that are maybe not top tier or on my watch list," and while "these are works that I would probably find out [about] eventually through citations...that takes three to four years for it to be cited in someone else's work."

Foreign social media sites were also described as an essential resource for staying apprised of developments in Asia. "It's very important in Chinese studies today to be active on social media and to get on Weibo, on WeChat, and just various websites, just to get a sense of what are the topics people are discussing, what are the hot issues." However, vetting information published overseas or in a different language presents a 
unique challenge because of weaker peer networks with scholars based overseas. "On the Chinese side of things, that's where it gets more difficult," said one scholar, "because it takes longer to read through it, so it takes longer to evaluate, right? And you don't know as many people to just ask...like, who's good and who's not good?”

\section{Digital Dilemmas}

The ability to find and access information on the Internet has transformed the way that Asian studies scholars conduct their research. Increased digitization of the primary and secondary sources scholars use has facilitated the discovery process by allowing them the chance to assess which sources are available at different locations prior to accessing them. While this has afforded scholars greater convenience in conducting their research in the U.S., this effect is magnified when they are able to digitally find and access information that is located in libraries and archives overseas. According to one scholar, "The first place you actually look nowadays is online. Then from there you go look for the places where you can physically find them." Online search engines like Google and library catalogs, including institution-specific catalogs or WorldCat, were listed as popular search tools, as were databases managed by institutions or governments in Asia, such as the China National Knowledge Infrastructure (CNKI). The Internet has also broadened the types of information available to Asian studies scholars, many of whom study cultural phenomena and who are able to extract primary information from social media and other websites. But while finding and accessing materials online has increased the ease with which scholars conduct their research in many aspects, it has simultaneously created a number of new challenges.

One of these challenges is that rates of digitization and the ability to access digital materials varies widely within and among regions of Asia. For instance, scholars researching in East Asia generally found that Korean institutes "scan a lot and they put up a lot [of] stuff online, so it's just really accessible," whereas in Japan and Taiwan, remote access to databases and other digitized government documents is only available to citizens of those countries, if not only in-person. In other regions, such as in South Asia, "there's not a lot of stuff online" despite increased digitization, while in Southeast Asia, the relative lack of peer-reviewed publications has scholars seeking out gray literature and other unpublished materials digitally to a greater extent. "There are so many government reports. Stuff I can find online...those are easily available from the government," said one scholar, although like public health scholars who also use gray literature extensively, the fact that it is rarely collected in one place and inconsistently published online makes finding it a challenge. ${ }^{5}$ Furthermore, scholars conducting

${ }^{5}$ See "Supporting the Changing Research Practices of Public Health Scholars," p.13-14. 
research in Southeast Asia acknowledge that "a lot of classic and important articles circulated as manuscripts for a long time before they were published," and were most easily located and accessed through a general search engine like Google Scholar.

Increased rates of digitization have also led to stronger barriers to accessing information in some countries due in part to geopolitical tensions, the West's history of colonization, and some governments' desire to maintain tight control over information dissemination. For example, scholars conducting research in China noted that "sometimes [those in charge of information access] close an archive or they don't let you see anything," but one scholar also noted that "after digitization the problem is worse. Because now they have more control over what they have." This observation was echoed by a scholar conducting research in Pakistan who said that reports that have been digitized are often password-protected, and "[i]n those cases I have found that I sometimes have to go to Pakistan and somebody in the ministry just passes me a printed report. So on the one hand there [are] a lot of materials available through international organizations, but some of the government publications seem harder to get than they would have been twenty years ago."

Perhaps because of these issues with accessing digital materials through official channels, scholars are turning to alternative types of information and online access points, although access can be limited in these cases as well. For instance, dissertations were widely discussed as an important source of secondary information, and while in places like China they are often preserved in the CNKI, scholars may not be able to access them if their institutions do not subscribe to that facet of the database. Lower levels of digital archiving in Southeast Asia also limit scholars' ability to access dissertations, though this may vary across disciplines as one archaeologist conceded that "universities in the region increasingly have repositories that hold theses."

Just as foreign social media sites were viewed as a vital tool for finding and keeping up with information, they are increasingly used to access information where it is otherwise restricted. As one scholar with colleagues researching Tibet explained, "Because they can't go there, because the Chinese government restricts access, they are using social media, they are looking at what people are writing." And when it comes to accessing formally-published information, some scholars are also turning to illicit methods like Kazakhstan's Sci-Hub, described by one scholar as "a miracle of criminal creativity" not only for removing the pay-wall from access, but also for the ease with which it can be used that has many scholars in Western universities choosing to obtain literature through this platform over legal channels. 
Many Asian studies scholars expressed that they are not particularly challenged in their ability to access information published in the U.S., such as books and academic journals that they use as secondary sources, as well as more mainstream primary sources like works by Confucius or The Tale of Genji. "I've been able to find everything in the library here," said one scholar, while another said, "I don't find myself looking for really obscure things...I rarely feel stymied when I'm trying to get ahold of stuff." If they are unable to procure a source immediately, scholars said that they can do so with relative ease, if with less convenience, through interlibrary loan (ILL) or through the common practice of utilizing resources at nearby universities. This was especially common for scholars at institutions with a less intensive research focus or with smaller Asian studies departments. For example, one scholar said, "[My institution] doesn't have many databases available...most of my research is done at [a neighboring institution]. My best friend is there. He can check stuff out for me." Another mentioned that while they find their librarians to be supportive of their research, "there are times when I had to rely on [a librarian at another institution]...just because she has the insight on where things are and how to get things. So that's just the challenge with, one, you're not at a research institute. And then two, you don't have a Korean studies librarian."

Asian studies scholars often expressed reluctance in asking for greater assistance to obtain the sources they need. Scholars at institutions with smaller Asian studies programs, and even those at institutions with robust programs but who are researching less prominent areas, often feel that they are not receiving adequate recognition and support from their host institutions. However, knowing that resources are limited, they are hesitant to ask that their libraries acquire literature or databases that will see little use beyond the specific scholars that request them. Said one scholar, "If it's really obscure, I feel guilty asking the library to order it since I'm the only full-time Southeast Asianist." These challenges are only exacerbated for scholars studying this region because it receives greater attention in Europe, with the result being that "a lot of books about Southeast Asia get published overseas and don't make it here, obviously unless I ask for them." Nor are they available through ILL, especially for literature published in Asia, as one scholar explained, "Well, interlibrary loan wouldn't have a lot of this material because the Asian language scholarship often resides in journals published by the universities where the scholars work, and so it would be an issue of something published at an international university." These comments suggest that access to information can be limited by an interlibrary loan system that does not necessarily capture literature published outside of the U.S., especially Asian literature, and that institutions should encourage scholars to make greater use of the library resources that are available to them to purchase information where necessary. 
Geopolitics act as another impediment to Asian studies scholars in the U.S. being able to access information originally published overseas. While some materials are available through U.S. academic libraries, scholars mentioned that the information they are able to access is dependent on what their institutions were able to acquire during periods of friendlier relations. For instance, one scholar noted that information from Pakistan is most easily accessible from the late 1940s to the 1970s, roughly following the trajectory of when U.S.-Pakistani relations were at their friendliest. Another scholar said that while their institution subscribes to the China National Knowledge Infrastructure (CNKI) database, "articles published before 1990 we can't get access to and I have to ask my friends in China to help me on those articles." These periods of openness also have an impact on the amount of Western literature produced on Asian countries, with a scholar researching in Southeast Asia noting that "Burma was pretty much closed to foreign researchers from 1962 till sometime in the 8os. So there's a big gap."

\section{Research in Asia}

Given the nature of their research, many of these scholars travel overseas to obtain information for their projects. Navigating bureaucracy is a challenge, however, where receiving a research visa is the first hurdle to overcome. While some scholars mentioned entering countries without visas and others experienced intimidation by security personnel, others were unable to enter at all to the detriment of their projects. "I actually got a grant a few years ago to go and then just couldn't get a research visa because it was a low point in U.S.-Pakistani relations," noted one scholar, while another said, "The proposal I wrote included western Thailand as well, but I haven't been to Thailand. I don't intend to [go] because I had a bad experience getting a permit there...and I don't have any reason to think that the situation has improved."

Once they are granted permission to enter the countries where they are conducting their research, scholars mentioned that finding information in the libraries and archives of Asian countries can be just as difficult due to a lack of finding aids and systematic categorization. "A lot of things have been either miscataloged or cataloged in ways that are not intuitive to me...they have multiple numbering systems for the material," one scholar said of libraries in Japan, although this issue spans across other Asian countries' libraries and archives as well. As previously mentioned, scholars struggle with effectively narrowing down their searches and filtering out information that is irrelevant to their studies. These challenges are only compounded when scholars also need to gain familiarity with the conventions of accessing information through archives beyond the West, with the effect that they are often uncertain about how much time to spend overseas-important for budgetary and visa considerations-and express a lack of confidence in their ability to obtain the amount of information they would like in the amount of time they are allotted. "You just don't know what the documents are going to 
be. It's hard to know how many days I need to budget to be there," said one scholar, while another stated that "you have to organize your time extremely efficiently without being very ambitious." To mitigate some of these concerns, scholars have turned to innovative methods to work with the information they do find, which will be discussed in the section "Working with Information."

Scholars conducting research in South and East Asia also perceive a general wariness and reluctance from locals to provide archival access to foreign researchers. In India, for instance, one scholar explained that there is little incentive to permit Western scholars into their archives, and in fact, that the West's history of colonization acts as a deterrent with potentially severe repercussions for archivists who do allow access to foreign scholars. For instance, as one scholar said, "If I get information and I do something with it and it turns out that it's controversial, they at home are like 'why'd you show it to that guy?' For me it makes me an academic star or whatever, for them all it does is jeopardize their job. So I understand the caution." Similarly, several others conducting research in China mentioned that while for a period of time archives were open, now "Chinese archives are increasingly closed...the situation in China is becoming much worse." And in Japan, which has a less contentious relationship with the West, archivists were perceived as reluctant to share information with scholars at all, worried that they would lose control of it-a not unfounded fear, according to one scholar's account that "a few years before I got to [an archive in Japan], a Japanese scholar had illicitly copied a lot of primary sources and then published them with a Japanese press, so they were really worried of anybody using certain materials."

That is not to say that every archive in South and East Asia is difficult to access; in South Korea, for instance, scholars found that "[m] ost of the archives are open to [the] public and scholars." However, even when scholars are able to access archives, there are other impediments to obtaining the information they need. In Southeast Asia, for instance, scholars see the lack of digitization as more of an issue than access to physical archives. More generally, scholars also described idiosyncratic issues like, "the hours of operation are often quite variable and dependent on perhaps that one person who has the key who feels like showing up for work that day," or, "Sometimes you see materials that are open and then the next time you go to the same archive they tell you that those materials don't exist." However, a common thread that connects Asian studies scholars' experiences is that they were more easily able to access information as they gained the trust of local officials, with one scholar saying that "as I got to know them, I think this is true anywhere, I got better cooperation.”

In fact, building relationships with locals and navigating bureaucracy to gain access to information is so commonplace, especially among scholars of South Asia, that this practice has been described as a "rite of passage." As one scholar said, "Research is about 
you know somebody, and then from there it goes," while another said, "Sometimes they do [give you access], sometimes they don't. It depends on what connections. You know how it is in South Asia." Obtaining information involves, according to Asian studies scholars, "a lot of just working people, a lot of tea drinking, this and that," but power dynamics can still thwart access to information if officials have no reason to grant it, with one scholar saying that in some countries all you need is a personal relationship with someone who knows someone, while in other countries personal relationships do not matter unless they need something from you.

The reluctance that scholars perceived by locals in providing them with archival access extends to interactions with human subjects. As described by one scholar, the main challenge is "getting access to people. For one thing, people are afraid to talk to a foreigner...[i]f I were Chinese it'd be easier because then you go into the villages and you're Chinese so they'll level with you. But they think I'm not trustworthy." In some cases, this sense of distrust is compounded by a subject that is especially sensitive, including topics pertaining to geographic boundaries, or which are downright illegal to study, such as topics pertaining to superstitious practices. But as some countries become more receptive to the West, scholars did report experiencing increased cooperation from local populations in gathering primary information. Research participants can even be eager to engage with scholars on less sensitive subjects, with one scholar saying that people were "pretty enthusiastic... about the idea of an American researcher coming to them and wanting to know about their art form and know about their traditions and recording it and bringing it [to the U.S.]."

\section{Language Barriers}

While it is not uncommon for Asian studies scholars to be native speakers and/or fluent in at least one Asian language, for those who are not, linguistic barriers were reported as a major challenge. Linguistic challenges are particularly acute for those working on linguistically diverse regions where knowledge of multiple languages is required for performing comparative analysis. This has implications for the methods scholars employ to discover and access information, whether that information is available as a print or electronic resource or through individuals serving as research participants.

Scholars describe relying on research assistants who do have the necessary language skills, as well as training others with fluency to collect human subject data for them. Those who utilize gray literature and other informally-published sources of information have also encountered challenges in being able to understand the reports produced by local NGOs or government agencies. "Because I don't speak Burmese, and I don't think it would be efficient for me to even start really...I depend on my colleagues to make sense of the gray literature," one scholar explained. Furthermore, when translations are 
available, a lack of a standard transliteration system can make it difficult for scholars to search for key words, titles, or mentions of historical figures.

The challenges of working with Asian language materials can alter the direction of these scholars' projects. For example, one scholar studying languages said that while corpora are an important resource for them, "they tend not to be available for the [Southeast Asian] languages I like to work on, which is kind of how I got into this project on French. It was [going] be so much easier to do because everything I needed was available.” Consequently, these scholars are subject to criticism for their reliance on materials that are easier to access, including their use of English-language sources; they are also critical of themselves for this reliance, with one scholar saying that "the English stuff is so much more readily available that you rely on it a lot more...like I'm saying, we become lazy researchers." Language is also a barrier for scholars in conducting research across countries to a greater extent. "I want to learn experiences from [other Asian countries] to apply to Vietnam," one scholar provided as an example, "but I don't have the language skills to do that."

These challenges may decrease in the future as OCR and other digital search functionalities become more advanced and widespread through discovery platforms. One scholar said that after downloading PDF versions of documents, "I'll run the whole document for the word 'elephant' in Vietnamese or the whole document for the word 'tiger'...By doing text searches through that, I can find a lot of $19^{\text {th }}$ century references to all these things." But while scholars working with Asian languages appreciate being able to use OCR to facilitate their research, they expressed that "there's a big split between pre-modern and modern" materials, as well as a split in functionality between materials in English and in other languages that reduces the utility of such technology.

The scholars also suggested that digital translation tools have not yet reached the point where they would be reliable as a replacement for language skills. One scholar commented that they used these tools as a complement to regular dictionaries and grammar reference books, saying that they used Google Translate "not to translate passages because that would usually result in gobbledygook, but as a sort of advanced dictionary." Another said that while Google Translate is helpful, it is not perfect or even especially accurate for some Asian languages. These comments suggest that while technology is primed to lessen these challenges, in the meantime scholars require greater support to reduce the barrier to research that working in an Asian language often poses. 


\section{Research Workflow Management}

The sensitivity surrounding some subjects or populations in Asia means that scholars often have to collect information in formats that best respect their participants' privacy. Creating digital copies of information obtained overseas was described as a favored tactic for gathering information quickly while on a tight travel timeline; however, scholars were often stymied by not being permitted to take photographs or, due to a lack of adequate infrastructure, make high-quality photocopies. Scholars prefer intuitive, user-friendly digital tools to manage their electronic information, maintain physical stacks of paper materials, and often employ idiosyncratic systems to easily assess the materials they already have. Storage throughout the duration of a project is a concern, especially with the advent of social media and other born-digital resources whose ephemeral nature makes them difficult to archive or access repeatedly. Long-term preservation poses another challenge as scholars contend with large quantities of information they wish to retain and as methods used to store information in the past become obsolete.

\section{Digitizing Information}

Asian studies scholars encounter challenges around information management from the earliest stages of their research process thanks to the heightened political sensitivity surrounding some information and the travel required to access it. Human subjects, particularly those in East and Southeast Asia, are often reluctant to have their interactions well-documented. This, in turn, impacts the ways in which these scholars collect and manage the information they gather through interviews and participant observation. "Some people, depending on how comfortable they appear, or not appear, I might have notes or I might have nothing," one scholar conducting research in China explained. They added that as far as using a recorder goes, "I don't think that's really very possible because there's a certain amount of political sensitivity." Similarly in Southeast Asia, another scholar said that "half of my fieldwork basically involves people who are in the vulnerable populations ... and rolling through the dark parts of Saigon with a tape recorder...it wouldn't play so well.”

Hand writing notes during or after an interaction is considered a safer way to collect information obtained verbally or visually while protecting participants' privacy, and in some cases scholars prefer to use tangible notebooks; however, this can lessen the depth of the data obtained as scholars are unable to reference back to recordings, as well as creates the additional challenge of where to store hard-copy data. In this respect, Asian studies scholars' experiences resonate with those of scholars conducting field research more widely, particularly in anthropological traditions. Similar to those scholars, the merits of how and to what extent human activity can be documented by researchers is an 
issue of ongoing concern and debate, but as political situations improve in some countries throughout Asia, scholars remarked that using a recorder and taking photographs have become more commonplace.

Scholars who use libraries and archives in Asia share a similar concern because they are unable to access or refer back to original sources once they leave the country, and they only have a limited amount of time to conduct research. To make the most of their time, Asian studies scholars regularly digitize hard-copy documents, artifacts, and images to collect as much information as possible prior to analyzing it, As one scholar said, "I just photographed everything I could since I didn't know if I'd be able to come back." But just as it was difficult to access these spaces, once inside scholars remarked that they often were not able to quickly gather information in ways that would be usable. "The problem is the sources are not allowed to leave the building, and not only that, you can't photocopy them. You can't even take a picture with your phone," one scholar conducting research in East Asia said, adding, "I was supposed to have like a photographic memory of all the various images in the book, and it doesn't make any sense." Another noted that at an archive in South Asia, "They do not allow you to take photos, that's for sure," and while they could purchase scans of the documents, "You had to pay 45 cents a page, so it's not cheap. The scans weren't very good, I have to say." Scholars are finding themselves unable to take advantage of technological advances because of the policies in place in so many repositories.

\section{Managing Information}

Scholars are employing digital methods to manage both print and electronic primary and secondary information once it is collected. These methods are often idiosyncratic, vary in their sophistication, and are meant to address scholars' main concern that they be able to easily determine the sources they have already obtained and analyzed. In some cases scholars rely on Microsoft Office and its various applications, such as Word-"I just use a Word document trying to write down all the information I have, what are the titles"-and Excel-"I keep a spreadsheet [of] all the statistical yearbooks I use all the time." One scholar even said that "for my own acquisition, I often take a picture of the cover...it goes to my computer, so I know I already got it." These files, as well as information downloaded from the internet, are saved to scholars' computers in folder systems that vary based on their needs. For instance, one scholar explained, "I have an 'article unread' folder and then when I read something, after I take notes on it, I swap it into the 'article' folder."

Bibliographic and qualitative coding software, such as EndNote, Mendeley, DEVONthink, Zotero, and Atlas TI, are also favored as a means of keeping track of print and electronic resources alike, as well as for their organizational capabilities that 
facilitate searching through electronic documents. "I think Zotero's incredibly powerful," said one scholar. "It's really useful when writing because then all your citations are all in order and come out perfectly, but it's also a way to organize your data so you can look at it in different ways and do searches and stuff." Using these tools with information in another language is difficult, however, with scholars observing that they lack features that would allow them to work easily with non-Roman scripts. "None of them can format multilingual entries the way I want to do it for my work. And I think if you're working in English, it's fine because you just Romanize everything...But for what I do, I feel like I want to preserve the original language form of my citations, as well as providing Romanized and translated forms."

While this scholar acknowledges that they simply may not have discovered how to use this feature yet if it exists, they also expressed that no one else in their department has found bibliographic software that can accomplish multilingual formatting. Scholars will also make use of Cloud-based platforms like Google Drive, One Drive, and Dropbox because they allow for easy sharing and searching for comments made by their collaborators, but they prefer tools with which they are already familiar and which they know their peers will feel comfortable using. As one scholar explained, "I have tried Google Drive, like the Google Doc thing, but...it looks like it's still more intuitive for people to just get it in their mailbox and work on it and send it out."

Despite the convenience that digitization affords scholars in conducting their research, many still prefer to read and take notes by hand because they "[find] it more intuitive to scribble as [they] read." Scholars manage tangible sources in an equally idiosyncratic manner, with one saying that they follow the Library of Congress classification system to facilitate cross-referencing with their library's stacks, while another employs a more informal system: "That stack that goes this way on the bookshelf? Those are books that I've already taken notes on....and then that bottom row over there above the binders, is a row more specifically dedicated to this project...if I own the book or I still need the book for something, then I'll put it back on that shelf." In fact, managing and storing information particular to one's own needs is such a crucial part of each scholar's research workflow that one even said that "each scholar in [their] field is kind of a mini-librarian."

\section{Storing, Preserving, and Sharing Information}

Asian studies scholars who have collected information in hard-copy throughout their careers concede that space is a problem, as evidenced by one scholar who said, "See, look at all these boxes...space is a challenge." As another-albeit extreme-example, one scholar has had to move beyond just boxes, explaining that "I have vast cabinets...I have to rent an apartment for those because there's no room in my office, and there's no room in my house." In general, scholars were loath to part with any information they 
accumulate because it can be difficult to obtain. This challenge is only compounded by the fact that in some cases, these scholars are dealing with primary information from extremely isolated countries or which concerns politically sensitive issues. They are therefore faced with the dilemma of how to store information that they will never be granted access to again. As one scholar said, "I actually have a whole pile of North Korean newspaper[s]...it's taking up a lot of space but I keep all of those because you never know when you need them."

With the emergence of social media, online news sources, and other born-digital tools, scholars are also having to contend with the challenges of capturing and storing information that is very ephemeral in nature. Scholars working with these types of information find that "web research is a whole other ballgame that is even more complicated. Although it's actually very easily accessible, right? It's not easily archivable.” They cite the rapid recycling of information associated with these platforms, where failure to immediately capture a post on Twitter or an online article can mean never being able to find it again, as well as the ease with which individuals can delete information. To capture these sources, scholars will download videos, reports, and even use the snipping tool to save social media posts and comments, but would benefit from the use of tools designed specifically to manage and store content from the Internet that also comply with data protection regulations.

Scholars are also concerned about the long-term availability of more traditional content made digitally available, such as through Google and its associated features, including Google Books and Google N-grams. This concern leads to uncertainty to the extent to which they should be storing and preserving the content they access from these platforms. As an example, one linguist using Google's N-grams to search phrases across corpora said that because these "are some of the biggest files that I've ever downloaded...there have been a few times when I have purged those from my computer because I simply didn't have room for [them], and I guess I hope that if I ever need them again, Google will still be making them available."

Many scholars are interested in sharing their data to ensure that their peers or future generations will have access to it, but they admitted that in the past they were not equipped to handle preservation and have consequently lost much of the data they gathered over the course of their careers-an issue that cuts across scholars in other fields as well. "I'm not even sure I would know how to go and retrieve the data for something that I wrote twenty years ago," said one scholar, while another stated that they "worry about format change-I mean, cause we used to all use those $3{ }^{1 / 2}$ inch floppy disks-where could you even read them now? I use computer tape...I still have the tape lying around. There's no way I can convert it." 
Conversion may not be the only solution, though, as tools that capture similar data exist and can act as a repository if scholars are willing to manually input their data. This scholar goes on to say that while they can't convert their tapes, "on the other hand, it's also kind of irrelevant because these genealogy programs are now available-and I could key in all that information." A different remedy to the issue of preservation would be to partner with the library from the outset. As one scholar who aims to collect several thousand personal stories from participants related, "I think it would be good if the library were partnering with this whole process, so we can tap into that expertise as well, about storage and retrieval and archiving and so on and so forth.”

\section{Outputs, Audience, and Impact}

Asian studies scholars are primarily concerned with the ability of their peers to access their research beyond the West. While their outputs are evaluated by their institutions based on their publishers' reputations and impact factor, not unlike evaluation mechanisms in other fields, in some instances these scholars were willing to trade off greater impact to publish where their work would be more easily accessible and affordable by scholars in Asia. They also post pre-prints or condensed versions of their publications on personal and professional networking sites, often in place of publishing in open access journals or using institutional repositories. Scholars reported that they are uncertain of the legitimacy of open access journals, and some found institutional repositories difficult to use or were not aware of their availability. Publication practices are a barrier to interdisciplinary collaborations, with scholars noting that they need to publish in their own disciplinary journals to establish their expertise on a given subject. Different levels of productivity required by scholars in different countries also restrict the ability of these scholars to engage in collaborative research with their peers overseas.

\section{Achieving Impact with Traditional Scholarly Outputs}

Asian studies scholars focus on producing traditional scholarly outputs in ways that are similar to that of scholars in other humanistic and/or social scientific-dominated fields. Their scholarship often takes the form of academic journal articles, monographs, or chapters in edited volumes. Humanities scholars tend to prefer publishing books whereas social scientists prefer journal articles. According to one humanist, "the book is the thing that drives your entire existence in academia," while another explained that the longer format made possible by books is desirable because the research that humanists tend to conduct "cannot be published in a short journal article." Social scientists continue to emphasize the importance of articles because "publication in academic journals weighs more than just writing a monograph or policy-related paper" when it comes to receiving credit for promotion considerations. However, some social scientists 
working with qualitative research methods, such as ethnography, find the longer format more appropriate for their research, and in general, scholars in both the social sciences and humanities must publish at least one monograph as well as journal articles to obtain tenure.

Asian studies scholars select journals to publish in based on their impact factor, reputation, disciplinary area, and the academic audiences they cater to. While these considerations are common to scholars in any field, those working in Asian studies must additionally consider whether to publish in an area-specific or discipline-specific journal, and whether they are targeting a Western audience or an Asian one. "If your particular article is simply Korea-focused, then I choose [a] Korea-focused journal," explained one scholar. "If it is a little bit of comparative work, a little bit of theoretical work, then I choose a disciplinary journal. If it is specifically for a Korean audience, then I choose journals published in Korea." Similar consideration is given to selecting which presses to submit book manuscripts to, with scholars most often choosing to publish with Western academic presses that have good reputations as a measure of their own scholarship's credibility. "For my books, it's all university press, because that's a desired publication thing for tenure. I avoid the commercial press so far," said one scholar. As in selecting a journal by disciplinary focus, scholars also select book publishers by the topics they tend to disseminate. For instance, one scholar said that "because I do pop culture, it might be the University of Minnesota Press, because they have a pop culture series...we have to be pretty judicious about where these things go, because they're not going to be so widely accepted."

However, these traditional valuation models are facing growing criticism as increasing digitization changes the way that people consume information. Because books are increasingly being produced in electronic formats and seeing wider dissemination as a result, in some fields, "edited anthologies are actually becoming more influential than even some journal articles." In some instances, scholars are also finding that a conventional book or journal does not display their research to its full effect. For example, one scholar who studies comics stated that "it was the right format" to publish online and open access because it enabled them to showcase their visuals without the space limitations of a printed page while granting their students easy access to their work.

Additionally, many scholars choose to produce outputs like codices, textbooks, maps, and atlases that have relatively little value within the academy, but which they find personally interesting to create or which they believe will be a more important contribution to their field than a simple article. Said one scholar of their desire to publish an outline and commentary on archival data, "It might not be the most prestigious thing and colleagues might not think much of it in the end, but I will make the argument all 
day and all night that this is more useful than me writing an article and placing it in the Journal of the American Academy of Religion, which five people are going to read.” This comment not only pertains to Asian studies scholars but to scholars in other humanistic and social scientific fields, who express frustration that these alternative academic outputs have nominal value in the eyes of a tenure or promotion committee, but are important sources of information for scholars.

Asian studies scholars remain concerned about the impact of their work and the effect that it has on their careers, and as a result they continue to pursue traditional publishing practices where the value of their outputs is well-defined. Nevertheless, these scholars share the concern that, because the often esoteric nature of their research appeals to a niche audience, going through conventional dissemination channels limits their readership and weakens their impact and tenure review packages. It also restricts their engagement with non-academic audiences and poses a barrier to access for their overseas counterparts. In a bid to reach both groups to a greater extent, Asian studies scholars are seeking out alternative formats and channels to disseminate their work, sometimes at the expense of formally receiving credit.

\section{Reaching the Public}

While not every Asian studies scholar wishes to be a public intellectual, the majority were enthusiastic about engaging the public with their research. "It's important for academics to try to keep the non-academic community engaged and interested in what we do, or we'll just be this group of elitists [who] don't really care about what is going on in the rest of the world," explained one scholar. Another was vehement in stating that "I really feel like all of this knowledge I have should be shared...There are so many people who don't have access to those files without paying and it's not fair." To make their work available to non-academic audiences, some scholars will publish in semi-academic journals-described as "public intellectual" print or electronic venues where scholars can contribute non-peer-reviewed pieces-or post their pre-prints or other versions of their work on personal websites, although they mention often having to simplify their research so that it can be more easily read by general audiences. They will also employ this tactic when conveying their research through blogs, essays, newspaper and magazine articles, and even through film.

By sharing their research with the public, these scholars hope to increase general knowledge on a part of the world that is growing in influence, as well as help to overcome a perceived divide between academics and the public. However, another reason for reaching a wider audience rests on the fact that if they were to only publish in traditional academic journals, their readership by peers in the academy would be relatively low due to the highly-specialized nature of some of their research. This could not only have a 
negative effect on scholars' chances of promotion and tenure, but also reduce the realworld application of their research and the personal satisfaction some scholars derive from being able to excite and engage others with the topics they find interesting. For example, one scholar said of a project, "I translated [a classic text] and put it online, free. And that just opened up the field. So that English translation has been translated into many languages, so it's all over the place."

Nevertheless, scholars can also face backlash in their efforts to reach a wider audience, as it may appear as though they are trying to profit off of or speak for events happening at the local level overseas. One scholar said that while their host institution encourages public engagement, among their peers in the Philippines there "would have been a very critical viewpoint of me trying to capitalize on the situation and get my name in The New York Times or something like that. That was actually said to me. And so, I paused." Such comments demonstrate that while scholars wish to increase the impact of their work beyond the academy, they must also be mindful of how to appropriately bring awareness to situations occurring other countries and cultures.

\section{Reaching Peers in Asia}

As the previous section suggests, many scholars have an interest in broadening their audiences; however, the main motivation they expressed for making their work more readily available was to provide their peers in Asia with access to the same resources. "If there is someone in a developing country...who doesn't have access to these things, it's important for them to be able to just grab whatever they need off of people's web pages," asserted one scholar. This sentiment was especially prevalent among scholars conducting research in South and Southeast Asia. These scholars recount their concerns that their peers working out of non-Western institutions are often unable to afford the cost of books published in the U.S. and that their libraries do not provide them with sufficient access to scholarly publications.

To enable this access, scholars will use the aforementioned strategies of posting their pre-prints online, including to professional academic networking sites like Academia.edu and ResearchGate. Some scholars will even upload final versions of their work to the Internet because they sense little risk of repercussions from doing so. For instance, one scholar noted that while they have not heard anything from their press so far, "If I do I expect it would be a cease and desist...I don't think anybody is going to come with handcuffs or anything." Other scholars choose to forego some credit by publishing with a slightly less reputable but still well-known press, with one scholar saying that "if I published with a strictly Indian publisher I wouldn't get tenure...but [Routledge] has a good reputation. It was the only one I could find with a good reputation that would sell my book for under $\$ 10$ in India"-in contrast to the $\$ 120$ it would have cost in the U.S.- 
"so I made a choice...where I knew I was giving up a little something here to gain a little something there."

\section{Academic Networking Sites, Repositories, and Open Access Journals}

Making their work as widely accessible as possible can also be beneficial to these scholars' careers by boosting their reputations outside of and inside the academy. For example, according to one scholar, uploading an article to an academic networking site "immediately increases the number of people that would read it." Sites like Academia.edu and ResearchGate were described as primary channels for disseminating work beyond formal publications, especially among those conducting research in East Asia. It is important to note, however, that they often conflated posting to these sites with making their work openly accessible despite their for-profit business models and membership requirements. Another method scholars could employ to make their work more widely available to other scholars and the public would be to place it in an institutional repository.

However, the method that scholars utilize the most is often dependent on the ease with which they can navigate these platforms, the likelihood that they will increase scholars' readership and citation counts, and scholars' awareness of other ways to make their work open. One scholar who utilizes their institutional repository does so because "it's locally based, it gets a lot of traffic for the library, it does good stuff, and [the librarians] made it really user-friendly." Conversely, another avoids their institutional repository because "it was quite user-unfriendly. You have to look around everywhere and get permission, make requests, and so on." Still others remarked that they post their work to Academia.edu because "I don't know where else to go" and "it is just the low hanging fruit. I did it because it was there, not because I think it is better than any other method." These comments are indicative of what several scholars have expressed-that they simply did not know that their institution has a repository. Another subset of scholars expressed distrust toward their institution's repository, with one saying that "someone would have to explain to me how [repositories] were being used before I [would feel] like I really wanted to engage in that more actively."

Scholars will also publish in open access journals, with one scholar saying that "the motivation [to do so] is to have more people read it, and indeed I got a lot of hits from some of my work...like my Google citation is pretty high.” Many Asian studies scholars remain cautious about publishing and/or making their work available through open access, though. Their concerns are similar to those of scholars in other fields: they are uncertain about the legality of publishing and posting online, and they consider many open access journals to be disreputable, and article processing charges in proprietary journals too costly. Additionally, scholars concede that those in more junior faculty 
positions are not able to make their work open to as great of an extent, with one scholar acknowledging that "faculty at the beginning...can't be totally open access because it has to be vetted for tenure," while another said that because "a lot of recognized, wellestablished journals are not open access...especially for tenure review, you have to publish your articles through those kinds of journals."

Furthermore, because open access journals are subject to these questions about their reputability, there is a concern that publishing in such a journal would negatively impact a foreign collaborator's career because of its electronic-only format. As one scholar expressed, "I think it would make a very big difference to the career of my Burmese collaborator that these materials be published as hard copy from a reputable press. I don't want to do him out of the opportunities that would come his way." In spite of this concern, the emphasis on achieving tenure as dictated by traditional valuation models

affects not just scholarly outputs and their reach beyond the academy, but also the ability of these scholars to work with their peers in the U.S. and, more importantly, from the actual countries they are studying.

\section{Publishing Practices as a Barrier to Collaboration}

Scholars adhere to different collaborative practices depending on their discipline within Asian studies, not unlike scholars in other fields. For instance, scholars in certain disciplines participate in few collaborative projects-"historians tend to work alone" was a common refrain-while other scholars, especially those in the social sciences, will draw on other disciplines and scholars with more expertise in those areas to better address their research questions. Scholars do not need to engage in collaborations to conduct interdisciplinary research, but the requirements to advance one's career can limit the extent to which they work with their peers in other disciplines. They discussed a need to publish in highly reputable disciplinary journals as opposed to Asian studies, area studies and/or other interdisciplinary journals to "establish excellence" among their peers who would evaluate them for promotion and tenure. As one interviewee explained, "If you're trying to get tenure...as a historian, well, then all the leading historians in your field better say that you are really, really good at history. They're less likely to give you credit for the things that you do outside the field."

The need to publish in highly reputable disciplinary journals as opposed to interdisciplinary Asian studies and/or area studies journals is particularly acute for early to mid-career scholars, with those choosing a different publishing strategy at their peril. As one interviewee explained, "What's atypical about my career is that I've done a lot of interdisciplinary work...This has been a problem in my career-I've been in rank associate for forever-because nothing ever looked quite right.” A frequently expressed frustration is that Asian studies scholars are often consigned to their own disciplines 
despite what many view as an opportunity to collaborate together to holistically address issues in a region that is gaining influence on the global stage. "The way the academic professions tend to be organized, particularly in this country, the United States, is they're very siloed," lamented one scholar. "So the anthropologists write in a certain set of places and the physicists write in another set of places, and the economists somewhere else," with the effect that scholars have little incentive to keep up with tangentially-related research, let alone to engage in collaborative projects.

Scholars in Asia and the U.S. find it difficult to collaborate because they prioritize different outputs to maintain and grow their careers. Scholars in East Asia, for instance, have different numbers of required publications-"For Korean scholars, they have to produce at least two articles a year"-different channels for publication-“[Japanese] universities all have publishing venues"-and different types of publications-"Their work was very different from, I guess, scholars in the United States. That is, they focus a lot of their work on the translations of primary sources," which one American scholar described as an output that would receive little credit in the U.S. as a form of scholarship. Varying standards can also cause outputs by scholars in Asia to be incompatible with U.S. journals, and further reduces the ability of scholars in the U.S. to collaborate with their peers overseas. As one scholar observed, "It's just hard to work together because institutions in the different countries require different productivity." But a lack of collaboration can be detrimental to scholarship, with some scholars commenting that their research would have less meaning if it didn't include Asian perspectives and that it would discourage greater engagement by their peers overseas if American scholars' research was only conducted within a Western framework. "If you live in the United States and write about Asia, I don't know how you can do it without a lot of collaboration," one scholar remarked. "If you were to lose touch with the places that you write about, I think it would have a funny timber, it would feel funny."

\section{Conclusion}

For nearly 100 years scholars in the U.S. have conducted research on Asia in a bid to better understand the continent's extensive history, diverse cultures, and variegated social, economic, and foreign policies. And while Asia's influence continues to grow on the world stage, the findings of this report highlight how the U.S. academy has struggled to keep up with these developments, which is reflected in the experiences scholars face when navigating the research infrastructure designed to support them in their work. The report examined Asian studies scholars' research experiences in depth by covering issues pertaining to information discovery and access, research workflow management, and developing outputs. These findings reveal two key underlying themes that cut across the issues of ensuring optimal research support in Asian studies in the future, structural 
limitations associated with the organizing logics in the Western academy, and the still unmet promises of technology to ease those structural limitations.

\section{Area Studies and the Structural Limits of the Western Academy}

The ways in which the academy structures research affiliations is often not aligned with Asian studies scholars' research aims. They struggle with engaging in collaborative research with peers in Asia because of varying conventions and standards, and often silo themselves into their disciplines because of the need to establish excellence in their own areas over interdisciplinary work. These scholars fear that the current structures that serve to silo them will ultimately inhibit their ability to produce meaningful research that holistically addresses questions on Asia. As Asia grows into its role as a global leader, however, the research these scholars conduct will become increasingly imperative and warrants greater support from the academy. Scholars also frequently remarked that it is time that area studies were re-conceptualized to incorporate theoretical perspectives beyond the West. The experiences of Asian studies scholars, therefore, also underscore how the challenges of Asian studies also have implications for the future viability of area studies at large.

The structurally marginal status of Asian studies as a form of area studies has implications for scholars' ability to conduct research and communicate the results of their work. Within the U.S. scholars report relatively few challenges with being able to find and access literature and other pertinent sources of information for their research, but the ease with which they are able to access them is often dependent on an institution's departmental size and prioritization of different Asian regions. Scholars make ample use of ILL or other nearby institutions' resources to compensate for when materials at their own institutions are lacking, but it is a challenge for even the largest, most robust research libraries, archives and special collections to meet their needs through the current approaches to collecting and making this content available through Western institutions. Asian studies scholars are primarily evaluated by their publishing records, but these standards have not evolved to reflect what they perceive as the increasing importance of engaging with peers in Asia. They currently employ workarounds to reconcile these competing value systems, such as by alternating between publishing in traditionally reputable Western venues and other venues more accessible to Asian peers (e.g. open access journals and book publishers that cater to markets overseas that do not have strong recognition in the West). 


\section{Deeper Technological Affordances: A Promise Still Unmet}

The majority of Asian studies scholars engage with technology constantly but only to the extent to which these tools enhance some core research functions that predate that technology's introduction, such as those pertaining to discovering and managing information digitally. Due to the geopolitics of research, technological advances, especially those associated with digitizing collections, have also made research more challenging in some cases by providing archivists and other officials greater control over the information that they share and with whom. Their scholarly environments continue to include a mix of digital and analog materials because some content that they rely on for their research, particularly which is produced beyond the West, continues to be unavailable digitally. By extension, scholars must manage personal collections of information in multiple formats. Similar to other humanistic and social scientific-fields, Asian studies scholars are generally not pursuing new methodological approaches enabled by digital technologies, such as those associated with the digital humanities or data science techniques.

There are a variety of technologies that have the potential to be especially beneficial to Asian studies scholars, such as OCR and AI-enabled automated translation. However, at the point of this study, these technologies had still not yet been developed and made available to an extent that the impact could be observed within this scholarly community. Perhaps most notable about this interim period is that scholars' perceptions of the promise of technological advancement vary based on the type of technology. Asian studies scholars are far more likely to report a desire for improved OCR than translation technologies. This likely reflects the extent to which linguistic expertise is perceived as a cornerstone of the field, and also possibly perceptions that linguistic expertise exceeds the potential of technological innovation.

Perhaps the greatest technological challenge facing Asian studies scholars is how little current research technology has been built out to meet their unique needs. This is particularly acute for primary content created in Asia, where no central discovery mechanism exists for content that is already available online. Initiatives for capturing and preserving born digital content produced in Asia for the purposes of scholarship are also nearly non-existent and also greatly vulnerable is some regions to potential censorship. Some information management tools, such as for citation management, are not equipped for handling non-Roman scripts. It is still unknown what Asian studies scholars' experiences will be when taking up emerging organizational tools for digitally managing self-captured primary content, such as Tropy, because this tool was launched 
after the research for this study was conducted. ${ }^{6}$ However, we anticipate that the linguistic challenges that Asian studies scholars' face with metadata functions in citation management software will also be an issue with primary content personal management systems without deliberate intervention.

\section{Ways Forward}

The structural and technological challenges Asian studies scholars face are mutually reinforcing: the siloing and marginalization that these scholars face, coupled with the added complexity and increased resource support needs of their work, leads to a paucity of purpose-built technology that could ameliorate some of these challenges. Structural solutions are necessary to ensure that the digital affordances of information work can be leveraged to its fullest potential for scholarship, such as cross-institutional, international collaborations for collecting, preserving, and making content available, and navigating the geopolitics of censored information. The recommendations that follow reflect these infrastructural needs, pointing to the dynamic work necessary to support Asian studies scholars' research activities in the years to come.

\section{Recommendations}

\section{University Administration}

- Develop new approaches to recognizing and fostering the dynamic work of area studies. The siloing and marginalization of area studies, including Asian studies, at many Western institutions, reinforces outdated and often problematic Western imaginings of Asia and forecloses possibilities for collaborative, inter- and multi-disciplinary work. Improving the support and visibility of research foregrounded within and across geographic locales, including Asia, is essential to ensuring Western institutions' effective participation in the global research community.

- Create more effective mechanisms to encourage and recognize interdisciplinary research and collaborations among U.S. scholars and their peers overseas, such as through tenure and promotion processes. Traditional models of evaluating scholars do not incentivize them to engage in research across other disciplines or with other scholars, especially those in Asia, with the potential to reduce the real-world impact of their research and restrict the ability of universities to promote global studies in line with their strategic aims.

- Ensure that metrics used to evaluate scholars recognize other forms of outputs that are meaningful to Asian studies scholars' research. Scholars expressed that they find nontraditional scholarly outputs, like indices and commentaries, to be a more valuable output for their peers than an article or monograph. However, they must continue publishing these

${ }^{6}$ More information on Tropy can be found here: https://tropy.org/. 
more traditional outputs as the main metric for their success. Scholars experience similar barriers to recognition when publishing in venues beyond the West, which they perceive as an important engagement mechanism.

\section{Libraries}

- Improve institutional repositories' functionality, including for data curation, and, increase outreach to encourage better use of this tool. Scholars commonly chose to post their research to personal websites or to professional networking sites over repositories because they found them difficult to navigate compared to other tools, did not know of their existence, or were uncertain of their utility.

- Establish new consortia or encourage greater use of existing models like the Center for Research Libraries to facilitate scholars' access to non-Western databases and other tangible materials. It is a challenge for even the largest North American institutions to provide access to materials originating beyond the West. This warrants new collaborative models, in addition to interlibrary loan, to ensure that scholars have access to the content they need. As the scholarly ecosystem in Asia is sometimes significantly different than in the West, particular collecting strategies, such as continuing to purchase "just in case" content and an emphasis on print-only materials will continue to be warranted.

- Develop resources and train scholars in information literacy, particularly for discovering and working with content in non-English languages. Scholars reported having to work around existing catalog systems to realize the full scope of their research, made more difficult by a lack of familiarity with key words at the start of a project, and struggled to refine their search results to only relevant information. They report that searching for content beyond the West requires different strategies and it would be helpful to have support in identifying and implementing those strategies.

- Work with scholars to identify and recognize high-quality non Western channels for publishing Asian studies scholarship. Asian Studies scholars based in the U.S. desire to publish beyond the West in order to engage as fully as possible with international research collaborators and other stakeholders. They experience challenges finding non Western publications that will be recognized in Western academic contexts, which also necessitates support in articulating that value more broadly, such as through improved non Western journal evaluation mechanisms.

- Work with scholars to capture and curate collections, especially born-digital information, and provide resources for collectors, scholars, and IT personnel to improve storage and preservation best practices. Scholars often amass their own private collections of tangible materials or digital copies, and increasingly utilize information that only exists in a digital format (e.g. social media posts, online news articles) and which is difficult to capture because of its ephemeral nature. They require greater support to adequately organize and store these materials throughout the duration of a project and for future use. At many institutions this will also require buy-in and collaboration from IT and others who have responsibility over designating and managing digital storage infrastructures. 


\section{Publishers}

- Improve programs that promote greater accessibility and affordability of Western publications to scholars beyond the West and non-Western publications to scholars in the West. In the current publishing landscape, U.S. Asian studies scholars must make difficult compromises between whether to publish in journals that will have impact in the Western academy or with the communities they engage with beyond the West.

- Refine metrics standards and tools to more effectively articulate the value of publishing diversity. Differing methods of measuring impact and reputability of Asian publications in their respective countries impedes the ability of U.S. scholars to engage in collaborative research with their peers overseas. Improving these metrics will help scholars navigate the complexities of the non-Western publishing landscape and help with the translational work of articulating the value of their publishing activities in Western academic contexts.

- Include a broader array of quality non-Western content in databases and indexes available to Western scholars. Scholars experience difficulty discovering materials published outside of the West, often having to travel and spend significant amounts of time browsing through libraries, archives, and bookstores to discover information relevant to their research.

\section{Research Tool Developers}

- Improve features in citation management software to allow greater functionality when working with non-Roman scripts. While many Asian studies scholars utilize tools like Zotero and Mendeley to keep track of their references, they remarked that they perform poorly with multilingual formatting.

- Develop tools that more effectively leverage OCR for non-English language materials, especially for photographs and scans. The ability to quickly scan texts for key words has facilitated research tremendously for Asian studies scholars, but these tools are currently best suited for digitized literature written in Roman scripts.

- Improve language translation software. These scholars often work in the languages of the countries they are studying and will supplement their language skills with digital translation tools, such as Google Translate, but they find that these tools are not yet able to provide translations with a sufficient level of accuracy to warrant great use.

- Create tools that facilitate both the personal collection of materials and the sharing of these collections. Scholars often curate their own collections of tangible and born-digital information and wish to share them with others, or have expressed a desire to be able to access information curated by others themselves. They require user-friendly tools to facilitate management and sharing of this information, similar to tools like Tropy that enable scholars to better organize information collected as photographs. 


\section{ITHAKA S+R}

\section{Funders}

- Develop opportunities for scaling the collection and preservation of born-digital content created in Asia. Collecting and preserving born-digital content at scale for research-purposes is a grand challenge that cuts across traditional institutional and geopolitical boundaries and includes a variety of stakeholders. Funders are uniquely poised to foster the collaborations and fund the infrastructure necessary for doing this work.

- Support initiatives focusing on exploratory technologies that will improve scholarly experiences working with and on non-Roman scripts. While translation functionality is improving, mainstream efforts are not focused on facilitating the complex work of scholarship. OCR functionality continues to lag for non-Roman scripts.

- Encourage initiatives that span geopolitical bounds. Scholars are interested in pursuing research on and across locales that defy traditional boundary lines. Funders are uniquely positioned to foster work that re-imagines how Asian studies is defined and delimited in the West. 


\section{Appendix 1: Research Teams and Local Reports}

\section{Arizona State University}

- Team member: Ralph Gabbard

- $\quad$ Report URL: https://repository.asu.edu/items/46520

\section{Claremont Colleges}

- Team members: Carrie Marsh, Xiuying Zou

- $\quad$ Report URL: http://scholarship.claremont.edu/library staff/60

\section{Harvard University}

- Team members: Michael Hopper, Ramona Islam Richard Lesage, Kuniko Yamada McVey

- $\quad$ Report URL: http://nrs.harvard.edu/urn-3:HUL.InstRepos:34956564

\section{Indiana University}

- Team members: Karen Stoll Farrell, Brian Winterman

- Report URL: http://hdl.handle.net/2022/21920

\section{Lafayette College}

- Team members: Michaela Kelly, Lijuan Xu

- Report URL: $\underline{\text { https://ldr.lafayette.edu/handle/10385/2288 }}$

\section{University of Maryland}

- Team members: Cynthia Sorrell, Yukako Tatsumi

- Report URL: http://hdl.handle.net/1903/20510

\section{Trinity University}

- Team member: Michael J. Hughes

- Report URL: https://digitalcommons.trinity.edu/lib faculty/92/ 


\section{University of Colorado Boulder}

- Team member: Xiang Li

- Report URL: https://scholar.colorado.edu/libr facpapers/107

University of California Los Angeles

- Team members: Jade Alburo, Tomoko Bialock, Su Chen, Hong Cheng, Sanghun Cho, David Hirsch

- Report URL: http://escholarship.org/uc/item/6vv2h6g8

University of Texas Austin

- Team members: Mary Rader, Bonnie Brown Real, Meng-fen Su

- $\quad$ Report URL: http://hdl.handle.net/2152/62941

University of Washington

- Team members: Deepa Banerjee, Judith A. Henchy, Zhijia Shen, Azusa Tanaka, Hyokyoung Yi

- $\quad$ Report URL: $\underline{\text { http://hdl.handle.net/1773/41351 }}$ 


\section{Appendix 2: Semi-Structured Interview Guide}

\section{Research Focus and Methods}

1. Describe your current research focus/projects.

2. How is your research situated within the field of Asian studies? [Probe for how/does their work engage with any other fields or disciplines?]

3. What research methods do you typically use to conduct your research? [Probe for how those methods relate to work done by others in Asian studies/in the other fields they engage with)

- Do you collaborate with others as part of your research? [If yes, probe for what these collaborations entail, who typically works on them and what the division of work is]

- Does your research elicit data? [If so, probe for what kinds of data typically elicited, how they incorporate this data into their final research outputs and how they manage and store this data for their ongoing use]

\section{Information Access and Discovery}

4. [Beyond the data your research produces] What kinds of primary information do you rely on to do your research?

- How do you locate this information?

- What are the greatest challenges you experience working with this kind of information?

- How do you manage and store this information for your ongoing use?

5. What kinds of secondary information do you rely on to do your research? E.g. monographs, peer reviewed articles.

- How do you locate this information?

- What are the greatest challenges you experience working with this kind of information?

- How do you manage and store this information for your ongoing use?

6. Think back to a past or ongoing research project where you faced challenges in the process of finding and accessing information.

- Describe these challenges.

- What could have been done to mitigate these challenges?

7. How do you keep up with trends in your field more broadly?

\section{Dissemination Practices}

8. Where do you typically publish your scholarly research? [Probe for kinds of publications and what disciplinary audiences they typically seek to engage with].

- Do you disseminate your research beyond scholarly publications? [If so, probe for where they publish and why they publish in these venues] 


\section{ITHAKA S+R}

- How do your publishing practices relate to those typical to your discipline?

9. Have you ever made your research data, materials or publications available through open access? (e.g. through an institutional repository, open access journal or journal option)

- If so, where and what has been your motivations for pursuing open dissemination channels? (i.e. required, for sharing, investment in open access principles)

- If no, why not?

\section{State of the Field and Wrapping Up}

10.If I gave you a magic wand that could help you with your research and publication process [except for more money or time] - what would you ask it to do?

11. What future challenges and opportunities do you see for the broader field of Asian studies?

12. Is there anything else about your experiences as a scholar of Asian studies and/or the Asian studies as a field that you think it is important for me to know that was not covered in the previous questions? 